\title{
Physicians Should Play a Role in Ensuring Safe Firearm Ownership
}

\author{
Stephen R. Holt, MD, MS, Julie Rosenbaum, MD, Matthew Ellman, MD, \\ Benjamin Doolittle, MD, and Daniel G. Tobin, MD
}

Yale University School of Medicine, New Haven, CT, USA.

The USA is unique among industrialized nations in its dramatic rate of firearm violence. Unfortunately, firearmrelated issues in America are politically divisive and fraught with controversy, thus impeding the study and implementation of safety strategies. Despite the lack of consensus, there is agreement that firearms should be kept away from individuals with criminal intent and those who are dangerous due to medical impairment. While predicting criminal intent remains challenging, assessment of medical impairment remains a viable target. One approach in which physicians could contribute their expertise includes training a subset of doctors to perform specialized medical evaluations as a prerequisite for gun ownership. Such a process is not unprecedented, as physicians currently have a role in protecting the public's safety through assessments for commercial drivers, pilots, and train operators. Certified physician examiners could conduct these evaluations with a focus on evaluating objective, skill-based metrics to limit potential evaluator bias. The results of the medical evaluation would then be considered by an existing regulatory body to determine if disqualifying criteria are present. This proposal provides a mechanism for trained physicians to meaningfully participate in addressing an alarming public health issue, while still working within existing legal frameworks.

KEY WORDS: gun violence; public health; evaluation; functional status.

$\mathrm{J}$ Gen Intern Med 34(8):1637-40

DOI: $10.1007 / \mathrm{s} 11606-019-05034-2$

() Society of General Internal Medicine 2019

$\mathrm{G}$ un violence, whether due to homicide, suicide, unintentional injury, or a "mass shooting" - an event where 4 or more people are killed ${ }^{1}$ - has become all too common in the USA, anguishing diverse communities across the country. While representing only a tiny fraction of the annual death toll from gun violence, mass shootings in Las Vegas, Orlando, Sutherland Springs, Sandy Hook, Parkland, and others have engendered a national conversation on how to reduce firearm

Received August 21, 2018

Revised February 5, 2019

Accepted April 4, 2019

Published online May 6, 2019 violence. In 2015 alone, over 35,000 Americans were killed by gunfire, two-thirds of which were suicides, ${ }^{2}$ a statistic that dramatically exceeds all other industrialized nations. ${ }^{3,4}$ Acknowledging that more Americans died of firearm violence in 2014 than of hypertension, ${ }^{5}$ then US Surgeon General Dr. Vivek Murthy declared firearm violence a national public health issue and suggested it warranted the same comprehensive approach that successfully reduced tobacco-related harms and motor vehicle collisions. ${ }^{6}$

The role physicians should play in reducing firearm violence has long been a matter of debate. Recently, the executive leadership of seven physician professional societies, in collaboration with the American Public Health Association and American Bar Association, released a position statement on the topic. ${ }^{7}$ In their self-titled "call to action," they suggest physicians should become involved with advocacy efforts, engage in firearm violence research, promote national discourse on the topic, and speak freely with their patients in the context of direct patient care. Like many other public health crises, however, firearm control efforts ultimately pit personal freedom against public safety, inevitably leading to divisions and controversy.

Nonetheless, advocates on both sides of the debate generally agree on a common principle: firearms should be kept out of the hands of those who might be a danger to themselves or others due to criminal intent or medical impairment. ${ }^{8}$ While efforts to determine criminal intent before firearm violence occurs are impractical, we propose a strategy in which physicians can contribute their expertise toward the determination of medical impairment. Specifically, we recommend that a medical evaluation serve as a prerequisite for firearm ownership, and that a subset of physicians become certified to perform these evaluations based on predetermined criteria.

The concept is based on precedent: physicians have long had a role in participating in activities to improve the public's health, weighing the balance between personal autonomy and the safety of others. For example, certifying medical evaluations are currently required for a broad range of personal and professional activities. A medical evaluation by a specially trained provider is generally required to obtain a license to drive a commercial vehicle, pilot an airplane, or adopt a child. Similarly, an evaluation of mental and physical health is often required before serving as a police officer, firefighter, or a 
seafarer on a commercial vessel. The rationale for these required evaluations is to protect personal and public safety. For instance, the Federal Aviation Administration mandates that all pilots be evaluated as medically fit to fly and specifies disqualifying conditions, including "angina pectoris, bipolar disorder, epilepsy, substance abuse and dependence, (and) personality disorder that is severe enough to have repeatedly manifested itself by overt acts." "Seafarers are required to undergo medical evaluations to reduce risks to other crew members and for the safe operation of the ship. ${ }^{10}$ Federal- or state-required medical certifications in these realms have been in effect for many years and widely accepted by the public and the medical community. ${ }^{11}$

We propose that physicians should play a comparable role in evaluating an individual's capacity to purchase, possess, and use a firearm safely. We recommend an approach similar to how physicians evaluate individuals for a commercial driver's license. Namely, doctors should complete a certification process to standardize their understanding of and ability to evaluate the physical and mental capacities required to own and operate a firearm safely. While this firearm safety evaluation would not be dramatically different from screenings that physicians already perform related to decreasing morbidity and mortality, participation in such programs should be voluntary and a registry of certified physicians should be made available to the public. By requiring special training and certification so that a subset of qualified health care providers perform the evaluations, the potential impact on existing doctor-patient relationships is minimized.

Importantly, the role of the physician in this model would be limited in scope; the doctor would complete a standardized evaluation of the firearm applicant and offer recommendations to the appropriate regulatory body but would not be the final decision-maker. The locus of such a regulatory body - state or federal-is one of several areas which would need to be determined via a broad discussion among diverse stakeholders. Importantly, the physician's political affiliation and personal beliefs regarding firearm ownership should have no relevance on the evaluation, which should focus solely on functional capacity and mental fitness. If, based on the physician's evaluation, the existing regulatory body concludes that an individual is unfit to own a firearm, that person should have the opportunity to appeal the decision and a method for reevaluation should be available. However, a physician's evaluation should be a critical part of the firearm ownership process so that otherwise undiagnosed and uncontrolled medical or psychiatric incapacity does not pose a threat to public safety. This role may be particularly important in older adults at risk of progressive cognitive impairment. ${ }^{11}$

This proposal requires the establishment of criteria as to what constitutes the requisite physical and mental health safety standards to safely own and operate a firearm. Without such a standard, firearm safety evaluations could be subject to a wide array of overt or subconscious biases. Limited survey-based research has demonstrated that non-standardized physician evaluations of patients applying for a concealed weapon permit result in inconsistent medical opinions. ${ }^{12}$ The development of evaluative standards and disqualifying criteria should be generated in a multidisciplinary manner with input from non-medical experts in the law and others with expertise in firearm safety. Yet, the physician's input is particularly important to assess for the presence of unstable physical and mental impairment. Importantly, whereas the relationship between gun violence and mental illness in general is complex, ${ }^{13}$ there is evidence that untreated psychotic states and persecutory delusions are associated with violent acts and would therefore be reasonable disqualifying criteria. ${ }^{14,}{ }^{15}$ Similarly, applicants with active suicidal or homicidal ideation or those whom a physician determines to be an imminent danger to themselves or others should be excluded as well; an acutely dangerous mental state that ethically or legally necessitates a confidentiality breach or involuntary commitment should similarly disqualify a firearm application.

Unlike gun ownership, these personal and professional activities requiring certifying medical evaluations are not specifically mentioned in the United States Constitution. Nonetheless, even constitutional rights have always been subject to limitations and regulations with a goal of public safety. While the Second Amendment protects the right to bear arms, numerous laws already exist which regulate certain features of firearms (e.g., silencers, shotgun barrel-length) and permit seizure of firearms from certain dangerous persons. For example, federal law makes it unlawful for certain persons to ship, transport, receive, or possess firearms or ammunition, including those with substance use disorders or a person "who has been adjudicated as a mental defective or has been committed to any mental institution." ${ }^{16}$ Similarly, the First Amendment protection of free speech has been regulated over a range of circumstances, including speech which is obscene, which is hate-based, or which may incite actions to harm others. Lastly, physicians have a well-established societal authority to restrict personal freedoms vis-a-vis involuntary treatment, quarantine, or hospitalization when persons are deemed unsafe to themselves or others.

Several countries, including Japan, Germany, India, Israel, and others, currently require an evaluation by a clinician as part of the process of purchasing a firearm. ${ }^{17}$ The collective experience of such countries may yield important insights that could inform the creation of US guidelines. By using objective task-based safety criteria, the impact of differing philosophies and political affiliations can be minimized. For example, "Does the applicant possess the visual acuity to point the firearm at an intended target?" Acknowledging that poor firearm storage practices have been directly linked to unintentional firearm injuries, ${ }^{18}$ "Does the applicant have sufficient short-term recall and memory to remember to safely unload and store a firearm?" The evaluator is not judging the "worth" of the applicant; rather, they are evaluating the applicant's ability to safely understand and implement the fundamental requirements for safe firearm ownership and use. 
As mentioned previously, it is unlikely that any evaluator could accurately identify the presence of criminal intent. Without a truthful declaration of purpose from an applicant, such intent is essentially unknowable. Past criminal activity should be considered by the regulatory agency reviewing applications and may directly disqualify someone from gun possession or use based on existing federal law. ${ }^{16}$ However, intent cannot directly be inferred from such information. Therefore, we recommend that the medical provider focus on issues related to medical and psychiatric fitness and predisposition toward violent behavior using a tool similar to the SaFETy Score (Serious fighting, Friend weapon carrying, community Environment, firearm Threats) proposed by Goldstick et al. ${ }^{19}$ This and similar tools can be used to predict violence risk, which may be the closest proxy available for future unsafe or violent gun use.

A final consideration in applying a new policy of physician assessment as a prerequisite for firearm ownership is the handling of the vast number of guns currently in circulation in the USA, estimated recently to be 393 million civilianowned firearms. ${ }^{20}$ To limit resistance to such a new policy, it seems prudent to focus on new firearm sales or licenses rather than previously purchased firearms. With the US's distinction of representing only $4 \%$ of the world's population but owning $46 \%$ of the world's entire stock of firearms, ${ }^{20}$ any policy directed toward current gun owners is unlikely to hold sway in the court of public opinion.

Undoubtedly, this process would be enhanced by highquality research on firearm risk and safety to guide the creation of evaluation standards. Regrettably, existing law limits the conduct of such research. In 1996, the Congress passed the Dickey Amendment, which mandated that "none of the funds made available for injury prevention and control at the Centers for Disease Control and Prevention (CDC) may be used to advocate or promote gun control." 21 This amendment effectively quashed any research initiative into gun violence which might have yielded information to guide such a risk evaluation. For now, we are limited to expert consensus as the primary tool to drive the creation of such a standard.

In summary, we believe that the medical profession has an established role and responsibility to protect public safety and should devote its expertise toward that objective, including safe firearm ownership and use. We also agree that physically or mentally impaired persons who cannot safely store or use a firearm should be prevented from doing so. Importantly, we also believe that this can be done in a manner that recognizes and supports a diverse set of beliefs regarding the possession and use of firearms in the USA, as well as existing legal frameworks. As a community of health care providers, it is incumbent upon us to approach the question of firearm safety from a medical and public safety perspective through the promotion and implementation of high-quality research, as well as the collaborative development of objective safety standards. Our proposal would provide a venue for specially trained physicians to address this alarming public health issue meaningfully, while still guided by the rule of law.

Acknowledgments: The authors wish to thank Stephen Latham, JD, $\mathrm{PhD}$, for his assistance with developing this piece.

Corresponding Author: Stephen R. Holt, MD, MS; Yale University School of Medicine, 1450 Chapel Street, Rm P-312, New Haven, CT, USA (e-mail: stephen.holt@yale.edu).

\section{Compliance with Ethical Standards:}

Conflict of Interest: The authors declare that they do not have a conflict of interest.

\section{REFERENCES}

1. Mass Murder with Firearms: Incidents and Victims, 1999-2013. Congressional Research Service, 2015. (Accessed 3/11/19, at https://fas. org/sgp/crs/misc/R44126.pdf.)

2. Murphy SL, Xu JQ, Kochanek KD, Curtin SC, Arias E. Deaths: Final data for 2015. National Vital Statistics Reports; vol 66 no 6. Hyattsville, MD: National Center for Health Statistics. 2017.

3. States with Weak Gun Laws and Higher Gun Ownership Lead Nation in Gun Deaths, New Data for 2015 Confirms. Violence Policy Center, 2017. (Accessed 3/11/19, at http://www.vpc.org/press/states-with-weak-gunlaws-and-higher-gun-ownership-lead-nation-in-gun-deaths-new-datafor-2015-confirms/.)

4. GBD Compare. Institute for Health Metrics and Evaluation, University of Washington, 2013. (Accessed 3/11/19, at https://vizhub.healthdata. org/gbd-compare/.)

5. Xu J, Murphy S, Kochanek K, Bastian B. Deaths: Final data for 2013. Hyattsville: National Center for Health Statistics; 2016.

6. Bernstein L. Surgeon General Vivek Murthy wants to move U.S. health care toward a 'prevention-based society'. The Washington Post, 2015. Accessed 4/29/2019, at https://www.washingtonpost.com/news/toyour-health/wp/2015/04/23/surgeon-general-vivek-murthy-wantstomove-u-s-health-care-toward-a-prevention-based-society/? noredirect $=$ on\&utm_term $=$. db4fdda594af.

7. Weinberger SE HD, Lawrence HC III, et al. Firearm-related injury and death in the united states: A call to action from 8 health professional organizations and the american bar association. Annals of Internal Medicine 2015;162:513-6.

8. Parker K, Horowitz J, Ingielnik R, Oliphant B, Brown A. America's complex relationship with guns: Pew Research Center; 2017.

9. Guide for Aviation Medical Examiners. Federal Aviation Administration, 2019. Accessed 4/29/2019, at https://www.faa.gov/about/office_org/ headquarters_offices/avs/offices/aam/ame/guide/media/guide.pdf.)

10. Guidelines on the medical examinations of seafarers. International Labour Office, 2013. (Accessed 3/11/19, at http://www.ilo.org/ wcmsp5/groups/public/\%2D\%2D-ed_dialogue/\%2D\%2D-sector/documents/normativeinstrument/wcms_174794.pdf.)

11. Betz ME, McCourt AD, Vernick JS, Ranney ML, Maust DT, Wintemute GJ. Firearms and dementia: Clinical considerations. Annals of Internal Medicine 2018;169:47-9.

12. Goldstein AO VA, Pierson J, Barnhouse KK, Tulsky JA, Richman BD. Physician Beliefs about Physical and Mental Competency of Patients Applying for Concealed Weapon Permits. Behavioral Sciences \& the Law 2015;33:238-45.

13. Metzl JM, MacLeish KT. Mental Illness, Mass Shootings, and the Politics of American Firearms. American Journal of Public Health 2015;105:240-9.

14. Large MM. Treatment of Psychosis and Risk Assessment for Violence. American Journal of Psychiatry 2014;171:256-8.

15. Keers R, Ullrich S, Destavola BL, Coid JW. Association of violence with emergence of persecutory delusions in untreated schizophrenia. The American journal of psychiatry 2014;171:332-9.

16. Gun Control Act: Identify Prohibited Persons. Bureau of Alcohol, Tobacco, Firearms and Explosives, 2016. (Accessed 3/11/19, at https://www.atf. gov/firearms/identify-prohibited-persons.) 
17. How to Buy a Gun in 15 Countries. The New York Times, 2018. (Accessed 3/11/19, at https://www.nytimes.com/interactive/2018/03/02/world/ international-gun-laws.html.)

18. Grossman DC, Mueller BA, Riedy C, et al. Gun storage practices and risk of youth suicide and unintentional firearm injuries. Jama 2005;293:707-14.

19. Goldstick JE, Carter PM, Walton MA, et al. Development of the safety score: A clinical screening tool for predicting future firearm violence risk. Annals of Internal Medicine 2017;166:707-14.

20. Ingraham $\mathrm{C}$. There are more guns than people in the United States, according to a new study of global firearm ownership. The Washington Post 2018.
21. Public Law 104-208. 104th Congress, 1996. Accessed 4/29/2019, at https://www.gpo.gov/fdsys/pkg/PLAW-104publ208/pdf/PLAW104publ208.pdf.

Publisher's Note Springer Nature remains neutral with regard to jurisdictional claims in published maps and institutional affiliations. 